\title{
Risk factors for the existence of attention deficit hyperactivity disorder symptoms in children with autism spectrum disorders
}

This article was published in the following Dove Press journal:

Neuropsychiatric Disease and Treatment

I5 June 2017

Number of times this article has been viewed

\author{
Anna Linda Lamanna \\ Francesco Craig \\ Emilia Matera \\ Marta Simone \\ Maura Buttiglione \\ Lucia Margari \\ Child Neuropsychiatry Unit, \\ Department of Basic Medical \\ Sciences, Neuroscience and Sense \\ Organs, University of Bari "Aldo \\ Moro", Bari, Italy
}

Correspondence: Lucia Margari Child Neuropsychiatry Unit, Department of Basic Medical Sciences, Neuroscience and Sense Organs, University of Bari "Aldo Moro", Piazza Giulio Cesare II, 70124 Bari, Italy

Tel +3980 5592829

Fax +3980 5595260

Email lucia.margari@uniba.it
Abstract: Over the years, several authors have reported symptoms of attention deficit hyperactivity disorder (ADHD) in patients with autism spectrum disorders (ASD); however, studies on the risk factors of ADHD symptoms in children with ASD are lacking. The aim of this cross-sectional study was to identify the risk factors for the development of ADHD symptoms in children with ASD. The sample consisted of 67 children with ASD who were assessed with Conner's Parent Rating Scale-Revised (CPRS-R), and with a semi-structured detailed interview administered to parents, to collect a series of clinical data such as coexisting somatic and neuropsychiatric problems and familial and pre/peri/postpartum risk factors. We found that $55 \%$ of ASD children exceeded the cut-off of CPRS-R Diagnostic and Statistical Manual of Mental Disorders, Fourth Edition (DSM-IV), total scale. The univariate analyses showed that children's age $(P=0.048)$, motor delay $(P=0.039)$, enuresis $(P=0.014)$, allergies $(P<0.01)$, comorbid oppositional defiant disorder $(P=0.026)$ and intellectual disabilities comorbidities $(P=0.034)$ were associated to the CPRS-R DSM-IV total score. Some familial predictors such as neuropsychiatric family history of intellectual disabilities $(P=0.003)$ and psychosis $(P=0.039)$ were related to the CPRS-R DSM-IV total score. In particular, a model including allergies $(P=0.000)$ and family history of psychosis $(P=0.03)$ explained $25 \%$ (corrected $\left.R^{2}=0.25\right)$ of the variance of the DSM-IV ADHD score. In conclusion, we identified some risk factors associated with the development of ADHD symptoms in ASD children that need to be studied further.

Keywords: neurodevelopmental disorders, autism spectrum disorders, ASD, attention deficit hyperactivity disorder, ADHD, risk factors

\section{Introduction}

ADHD and ASD are neurodevelopmental disorders. According to the Diagnostic and Statistical Manual of Mental Disorders 5, ${ }^{1}$ ADHD is characterized by inattention and hyperactivity/impulsivity, while ASD is characterized by deficit in social interaction skills and in social communication as well as repetitive and restricted behavior and interests.

Epidemiological studies report that around $30 \%-80 \%$ of children with ASD meet the criteria for ADHD and that around 20\%-50\% of children with ADHD meet the criteria for ASD. ${ }^{2-5}$

There is evidence of an overlap between ASD and ADHD, including clinical, neuroanatomic and genetic research. Studies that have assessed some clinical features, such as executive control and aggression, in samples of children with ASD and ADHD, indicated a shared behavioral alteration in the two disorders. ${ }^{6-8}$

Lundström et $\mathrm{al}^{9}$ showed that there is a correlation between autistic traits and traits of other disorders, and that the correlation between them is largely mediated by 
genetic factors. In a review study, Taurines et a ${ }^{10}$ suggest that comorbidity between ASD and ADHD is caused by overlapping genetic or nongenetic biological risk factors.

Furthermore, several studies have described, in children with ADHD, disturbed social functioning, ${ }^{11-13}$ subclinical ASD symptoms, ${ }^{6,14}$ including emotion-processing difficulties, ${ }^{15-17}$ and autistic traits. ${ }^{18-20}$ In a study which compared gray matter volumes in patients with ASD and ADHD, Brieber et $\mathrm{al}^{21}$ found gray matter reductions in the left medial temporal lobe and higher gray matter volumes in the left inferior parietal cortex, in both disorders. Behavioral genetic studies, as well as research about familial aggregation ${ }^{5,22,23}$ and twin studies, ${ }^{5,24,25}$ show that ASD symptoms are hereditary within ADHD families, as indicated by elevated levels of ASD symptoms in affected and unaffected siblings of ADHD probands. The genetic correlation between ADHD and ASD suggests that a substantial part of the genetic influences on ADHD and ASD symptoms can be shared by the two disorders. Molecular genetic research about candidate genes, ${ }^{26-33}$ overlapping linkage studies, ${ }^{34-37}$ and genome-wide association studies ${ }^{38}$ suggest genetic risk loci, single-nucleotide polymorphisms and rare mutations are shared in individuals with ASD and ADHD. Given the high prevalence of comorbidity between ADHD and ASD, we hypothesize that both disorders may share common risk factors. In a study about risk factors of ASD symptoms in children with ADHD, including genetic factors and pregnancy and perinatal factors, it was found that perinatal risk factors interacting with catechol O-methyltransferase and the serotonin transporter gene predict ASD symptoms in children with ADHD. ${ }^{13}$

Some authors have identified language delay, motor coordination deficits, ODD, CD, maternal autistic traits, hyperactive symptoms and several psychosocial environmental risk factors as predictors of autistic symptoms in children with ADHD. ${ }^{39-41}$ On the other hand, we found no studies in the literature about predictors of ADHD symptoms in children with ASD. For this reason, it is important to examine risk factors for the development of ADHD symptoms in ASD because co-occurring psychiatric symptoms may negatively affect individual's social and academic functioning. There is some evidence that when ADHD is comorbid with ASD, the risk for increased severity of psychosocial problems and maladaptive behaviors increases..$^{42}$ Considering the several evidences about the overlap between ASD and ADHD, we hypothesized that the specific associated and risk factors for ADHD may be the same factors that increase the ADHD symptoms in children with ASD. In the current study, we considered child somatic or neuropsychiatric problems as possible factors associated with ADHD symptoms, while familial and pregnancy factors as possible predictors/risk factors of ADHD symptoms. Therefore, the aim of this crosssectional study was to identify associated and risk factors for the development of ADHD symptoms in population cohort of children with ASD.

\section{Methods}

The participants were recruited during hospitalization and outpatient visits, in the period between January 2011 and November 2013. The administration of the assessment tools and the semi-structured interview were undertaken by child and adolescent psychiatrists and psychologists who had undergone intensive training in the administration of these procedures. The study was approved by the local ethical committee "Azienda Ospedaliero-Universitaria Consorziale Policlinico di Bari” (DNr: 2012/592); all the parents who were interviewed provided written consent.

\section{Participants}

All patients were enrolled at the Child Neuropsychiatry Unit of the University Hospital of Bari (Puglia, Italy). Puglia is a vast region in Southern Italy, where the rates of children with ASD or ADHD are consistent with epidemiological Italian data. Exclusion criteria included severe intellectual disabilities (IQ <35), Rett syndrome, a known genetic syndrome or any other severe medical condition (ie, an history of serious head injury, encephalitis or tumors) and nonItalian-speaking parents.

\section{Clinical diagnosis of the ASD group}

ASD was diagnosed according to the DSM-IV-TR criteria, supported by the ADOS-G, the ADI-R and the SCQ. The ADOS-G is a session of semi-structured observation that consists of various activities that allow the examiner to observe the social and communicative behaviors for the diagnosis of ASD. ${ }^{43}$ The ADI-R is a wide-ranging structured interview addressed to parents, in order to produce a full range of information on child development and the presence of autistic symptoms. ${ }^{44}$ The SCQ was developed as a companion tool to the ADI-R and shows good psychometric properties. ${ }^{45}$

Intelligence testing was performed on each subject enrolled in the study by standardized intelligence test, in relation to age and presence/absence of verbal language, and included the Wechsler Intelligence Scale for Children (WISC-III) ${ }^{46}$ the Wechsler Preschool and Primary Scale of Intelligence (WPPSI) ${ }^{47}$ and the revised Leiter International Performances Scales (LEITER-R). ${ }^{48}$ 


\section{Assessment}

Demographic and clinical data were collected about gender, age, IQ, head circumference and BMI. The assessment included the administration of clinical standardized scales including the CPRS-R long version, including 80 items, validated for the Italian population. ${ }^{49}$ Furthermore, a semistructured detailed interview was administrated to parents or mothers of the ASD children to collect a series of clinical data. The CPRS-R and retrospective semi-structured interview were administered when ASD diagnosis was confirmed during hospitalization and outpatient visits. The CPRS-R is a parent-report measure that assesses children's problem behaviors, particularly symptoms of ADHD and related disorders (including oppositional defiant disorder and CD). The CPRS-R is frequently used in several studies. The area assessed by CPRS-R includes conduct problems, hyperactivity, inattention, aggression, anxiety, somatic complain, fears, obsessive compulsive behavior and school adjustment problems. Each item is to be rated by the parent on a four-part scale of "not at all", "just a little", "pretty much" or "very much" with scores of $0,1,2$ and 3 for these respective responses.

The retrospective semi-structured interview was developed ad hoc for the current study to collect a series of data, to assess risk factors associated with ADHD symptoms grouped into (1) coexisting somatic or neuropsychiatric problems, (2) familial predictors and (3) pregnancy and birth factors.

(1) Current somatic or neuropsychiatric problems included neuropsychiatric comorbidity, neurodevelopmental delay (motor or speech delay and history of enuresis), minor neurological signs (ie, clumsiness), abnormalities in EEG measured at the same time of the clinical evaluation of the patient, allergies and/or immunological diseases and obesity (BMI above the 95th percentile). Neuropsychiatric comorbidities were diagnosed by clinical evaluation according to DSM-IV-TR criteria.

(2) Familial predictors included a family history of neuropsychiatric disorders, parent's age at birth of the child and psychosocial risk factors. All parents were asked whether there are family members with a diagnosis of neuropsychiatric disorders. Neuropsychiatric family history comprehended neurological history (epilepsy, migraine, cerebral palsy) and psychiatric history (intellectual disabilities, specific learning disorders, ADHD, ASD, anxiety disorders, mood disorders, psychosis, tic disorders, substance abuse) and psychosocial risk factors (absence of a parent, quarrels, parental separation/divorce, excessive severity, excessive worries, special predilections, deaths in the family, hospitalizations, institutional education outside the family, migration, frequent removals, frequent changes of school classes, discrimination and adverse school circumstances, severe financial difficulties, belonging to a group of disadvantage, very inadequate home, not fluent in the local language).

(3) Pre/peri- and postpartum risk factors included both risk factors for a high-risk pregnancy and risk factors implicated in ADHD.

Prepartum risk factors comprised abortions, threatened miscarriage, maternal smoking, infections, preeclampsia, medications during pregnancy, placental abruption, gestational diabetes and intrauterine growth retardation. Peripartum risk factors included premature birth, low birth weight (newborn weighed 2,500 g or less), difficult delivery, respiratory distress and perinatal cyanosis. Postpartum risk factors included early infections, respiratory distress and cardiac rhythm disturbances in the neonatal period.

\section{Statistical analysis}

All demographic and clinical variables were subjected to statistical analysis. Regression analyses or analysis of variance with the Conner's DSM-IV ADHD score (examined dimensionally) as dependent variable was conducted to explore the univariate association with the following independent variables (examined categorically): (1) coexisting somatic or neuropsychiatric problems (neuropsychiatric comorbidities, neurodevelopment delay, minor neurological signs and EEG abnormalities), (2) familial predictors (family history of neuropsychiatric disorders, parent's age at birth of the child and psychosocial risk factors) and (3) pregnancy and birth factors (pre/peri- and postpartum risk factors). Putting together the results obtained, the independent variables that showed a $P$-value of $<0.05$ in univariate analyses were included as predictors or associated factors in the multiple linear regression analysis, while the risk factors that did not show an association in the multiple regression analysis $(P \leq 0.05)$ were excluded by backward selection from the model. The $R^{2}$ value was calculated in order to evaluate the goodness of fit about the model and included risk factors (observed versus estimated). Statistical significance was considered for $P$-values $<0.05$. We used the Statistical Package for Social Science 20 software.

\section{Results}

Out of 84 patients, four were excluded from the study because they failed to meet the inclusion criteria or were unwilling to participate. In addition, 13 children were excluded from the study 
because the cognitive assessment was not performed due to low cooperation. The final sample consisted of 67 children with ASD (57 males and 10 females; mean age 91.9 \pm 52.2 months).

The mean IQ score of the ASD sample was 79.4 \pm 23.8 ; in particular, normal intellectual function (IQ >84) was found in $42(63 \%)$ children, borderline intellectual level $(71<$ IQ $<84)$ in eight $(12 \%)$ children, mild intellectual disability $(50-55<$ IQ $<70)$ in nine $(13 \%)$ children and moderate intellectual disability $(35-40<$ IQ $<50-55)$ in eight (12\%) children. According to DSM-IV-TR criteria, autistic disorder was diagnosed in 10 (15\%) children, Asperger syndrome in eight (12\%) children and pervasive developmental disorder not otherwise specified in 49 (73\%) children. We found that $55 \%$ of ASD patients met the cut-offs for ADHD diagnosis at CPRS-R DSM-IV total subscale (mean score: 65.4 \pm 14 ), 50\% at CPRS-R DSM-IV-Inattentive (mean score: 64.4 \pm 13.9 ) and $43 \%$ at CPRS-R DSM-IV-HyperactiveImpulsive (mean score: $60.8 \pm 14$ ).

\section{Factors associated with ADHD symptoms in ASD sample}

(1) Frequencies and univariate analyses of coexisting somatic or neuropsychiatric problems are reported in Table 1.

Table I Univariate correlation of coexisting somatic or neuropsychiatric problems with CPRS-R DSM-IV ADHD scores in children with ASD

\begin{tabular}{|c|c|c|c|}
\hline $\begin{array}{l}\text { Coexisting somatic or } \\
\text { neuropsychiatric problems }\end{array}$ & $\mathbf{N}(\%)$ & Mean & $P$-value \\
\hline Gender (male) & 57 (85\%) & 0.124 & 0.174 \\
\hline Age (mean $\pm S D)$ & $88.12 \pm 44.1$ & 0.207 & $0.048^{*}$ \\
\hline $\mathrm{IQ}($ mean $\pm \mathrm{SD})$ & $66.9 \pm 37.1$ & -59 & 0.33 \\
\hline Macrocephaly & $7(10 \%)$ & $-0.14 \mid$ & 0.144 \\
\hline Obesity (BMI >95th percentile) & $19(28 \%)$ & -0.141 & 0.195 \\
\hline Motor delay & $19(28 \%)$ & 0.231 & $0.039 *$ \\
\hline Speech delay & $59(88 \%)$ & -0.177 & 0.189 \\
\hline Enuresis & $22(32 \%)$ & 0.285 & $0.014 *$ \\
\hline Minor neurological signs & $37(52 \%)$ & 0.053 & 0.353 \\
\hline EEG abnormalities & $12(18 \%)$ & 0.064 & 0.315 \\
\hline Allergies & $20(30 \%)$ & 0.474 & $0.0001 *$ \\
\hline \multicolumn{4}{|l|}{ Neuropsychiatric comorbidities } \\
\hline Tic disorders & $7(10 \%)$ & -0.015 & 0.454 \\
\hline ODD & I (I.5\%) & 0.255 & $0.026 *$ \\
\hline Intellectual disabilities & $15(22 \%)$ & 0.24 & $0.034 *$ \\
\hline Anxiety disorders & I (I.5\%) & 0.162 & 0.11 \\
\hline Sleep disorders & I (I.5\%) & -0.075 & 0.287 \\
\hline Mood disorders & I (I.5\%) & 0.145 & 0.136 \\
\hline
\end{tabular}

Note: $* p<0.05$.

Abbreviations: CPRS-R, Conner's Parent Rating Scale-Revised; DSM-IV, Diagnostic and Statistical Manual of Mental Disorders, Fourth Edition; ADHD, attention deficit hyperactivity disorder; ASD, autism spectrum disorder; IQ, intelligent quotient; BMI, body mass index; EEG, electroencephalogram; ODD, comorbid oppositional defiant disorder; SD, standard deviation.
The results showed that children's age $(P=0.048)$, motor delay $(P=0.039)$, enuresis $(P=0.014)$, allergies $(P<0.001)$, ODD $(P=0.026)$ and intellectual disabilities comorbidities $(P=0.034)$ were associated to the Conner's DSM-IV total score.

(2) Frequencies and univariate analyses of familial predictors are reported in Table 2. The results showed that neuropsychiatric family history of intellectual disabilities $(P=0.003)$ and psychosis $(P=0.039)$ was related to the CPRS-R DSM-IV total score.

(3) Frequencies and univariate analyses of the pregnancy and birth factors are reported in Table 3.

We have not found a significant association between specific risk factors and CPRS-R DSM-IV total score.

The associated factors were included in a multiple linear regression model with the CPRS-R DSM-IV total scores as dependent variable. Children's age, motor delay, enuresis, ODD and intellectual disabilities comorbidities and neuropsychiatric family history of intellectual disabilities were excluded by backward selection from the model. The final model included family history of allergies $(F=3.84, P=0.001)$ and family history of psychosis $(F=2.22, P=0.03)$. In ASD

Table 2 Univariate correlation of familiar predictors with CPRS-R DSM-IV ADHD scores in children with ASD

\begin{tabular}{llll}
\hline Familiar predictors & N (\%) & Mean & P-value \\
\hline Neurological familiality & & & \\
$\quad$ Migraine & $9(13 \%)$ & 202 & 0.062 \\
Epilepsy & $17(25 \%)$ & -0.06 & 0.327 \\
Cerebral palsy & $4(6 \%)$ & $-0.17 \mid$ & 0.097 \\
Psychiatric familiality & & & \\
Intellectual disabilities & $12(18 \%)$ & 0.355 & $0.003 *$ \\
Specific learning disorders & $3(4 \%)$ & -0.088 & 0.253 \\
Tic disorders & $6(9 \%)$ & 0.083 & 0.266 \\
Psychosis & $12(18 \%)$ & 0.231 & $0.039 *$ \\
Anxiety disorders & $12(18 \%)$ & 0.165 & 0.106 \\
Depression & $12(18 \%)$ & 0.075 & 0.285 \\
Substance abuse & $1(1.5 \%)$ & 0.162 & 0.11 \\
Autism spectrum disorders & $3(4.5 \%)$ & 0.022 & 0.434 \\
ADHD & $2(3 \%)$ & 0.189 & 0.076 \\
Mother's age (mean \pm SD) & $38.5 \pm 5.9$ & -0.106 & 0.213 \\
Father's age (mean \pm SD) & $41.8 \pm 6.6$ & -0.104 & 0.216 \\
Psychosocial risk factors ${ }^{\mathrm{a}}$ & $16(30 \%)$ & $-0.03 \mid$ & 0.408 \\
\hline
\end{tabular}

Notes: ${ }^{*} P<0.05$. ${ }^{\mathrm{a}}$ Abnormal intrafamilial relationship patterns and dysfunctional parenting (absence of a parent, quarrels, parental separation/divorce, excessive severity, excessive worries, special predilections), deaths in the family, hospitalizations, psychiatric disorder or disability in parent or sibling, institutional education outside the family, migration, frequent removals, frequent changes of school classes, discrimination and adverse school circumstances (ie, bullying), severe financial difficulties, belonging to a group of disadvantage, very inadequate home and not fluent in the local language.

Abbreviations: CPRS-R, Conner's Parent Rating Scale-Revised; DSM-IV, Diagnostic and Statistical Manual of Mental Disorders, Fourth Edition; ADHD, attention deficit hyperactivity disorder; ASD, autism spectrum disorder; SD, standard deviation. 
Table 3 Univariate correlation of pregnancy risk factors with CPRS-R DSM-IV ADHD scores in children with ASD

\begin{tabular}{llll}
\hline Pregnancy risk factors & $\mathbf{N}(\%)$ & $\boldsymbol{F}$ value, $\boldsymbol{r}_{\mathrm{p}}$ & $\boldsymbol{P}$-value \\
\hline Recurrent abortions & $9(13 \%)$ & -0.072 & 0.293 \\
Threatened miscarriage & $\mathrm{I}(15 \%)$ & 0.078 & 0.28 \\
Maternal smoking & $8(11.9 \%)$ & 0.173 & 0.095 \\
Infections & $\mathrm{I}(1.5 \%)$ & 0.164 & 0.95 \\
Preeclampsia & $3(4.5 \%)$ & $0.19 \mathrm{I}$ & 0.073 \\
Medications during pregnancy & $4(6 \%)$ & -0.127 & 0.17 \\
Placental abruption & $\mathrm{I}(1.5 \%)$ & 0.12 & 0.183 \\
Gestational diabetes & $2(3 \%)$ & -0.082 & 0.267 \\
Intrauterine growth retardation & $\mathrm{I}(1.5 \%)$ & 0.179 & 0.087 \\
Peripartum risk factors & & & 0.489 \\
$\quad$ Premature birth & $8(12 \%)$ & 0.189 & 0.18 \\
$\quad$ Low birth weight & $10(15 \%)$ & 0.202 & 0.062 \\
$\quad$ Difficult delivery & $7(10 \%)$ & 0.231 & 0.342 \\
$\quad$ Perinatal cyanosis & $3(4.5 \%)$ & 0.056 & 0.336 \\
Postpartum risk factors & & & \\
$\quad$ Early infections & $4(6 \%)$ & 0.016 & 0.452 \\
$\quad$ Respiratory distress & $\mathrm{I}(1.5 \%)$ & -0.004 & 0.488 \\
$\quad$ Neonatal cardiac rhythm & $2(3 \%)$ & 0.08 & 0.272 \\
disturbances & & & \\
\hline
\end{tabular}

Note: No statistically significant difference was found.

Abbreviations: CPRS-R, Conner's Parent Rating Scale-Revised; DSM-IV, Diagnostic and Statistical Manual of Mental Disorders, Fourth Edition; ADHD, attention deficit hyperactivity disorder; ASD, autism spectrum disorder.

group, corrected $R^{2}=0.25$ indicated that family history of allergies $(\beta=0.39$; CI $6.31-21.03)$ and family history of psychosis $(\beta=0.22$; CI $2.01-23.6)$ explained $25 \%$ of the variance of the Conner's DSM-IV total score. The multiple linear regression model with the total CPRS-R DSM-IV score as dependent variable is shown in Table 4.

\section{Discussion}

Over the years, several authors have reported symptoms of inattention/hyperactivity in patients with ASD..$^{50,51}$ More

Table 4 Factors associated with increased DSM-IV ADHD scores in children with ASD

\begin{tabular}{lllll}
\hline Factors associated & $\boldsymbol{t}$ & $\boldsymbol{\beta}$ & $\mathrm{Cl}_{95 \%}$ for $\boldsymbol{\beta}$ & $\boldsymbol{P}$-value \\
\hline Age & $\mathrm{I} .66$ & 0.23 & -0.16 to 0.16 & 0.1 \\
Motor delay & $\mathrm{I} .57$ & 0.17 & -13.8 to 1.66 & 0.12 \\
Intellectual disabilities & 0.72 & 0.14 & -12.8 to 13.66 & $0.9 \mathrm{I}$ \\
Enuresis & $\mathrm{I} .77$ & 0.3 & -0.7 to II.4 & 0.83 \\
ODD & 0.29 & 1.62 & -9.04 to 12.64 & 0.76 \\
NPF for intellectual disabilities & 0.19 & 1.53 & -2.5 to 18.4 & 0.13 \\
Allergies & 3.84 & 0.39 & $6.3 \mathrm{I}-21.03$ & $0.00 \mathrm{I}^{*}$ \\
NPF for psychosis & 2.22 & 0.22 & $2.0 \mathrm{I}-23.6$ & $0.03^{*}$ \\
\hline
\end{tabular}

Notes: Model with two predictors (allergies and NPF for psychosis): $R^{2}=0.28$ (corrected $R^{2}=0.25$ ). $* P<0.05$.

Abbreviations: DSM-IV, Diagnostic and Statistical Manual of Mental Disorders, Fourth Edition; ADHD, attention deficit hyperactivity disorder; ASD, autism spectrum disorder; ODD, comorbid oppositional defiant disorder; NPF, neuropsychiatric familiality. recently, Gjevik et a ${ }^{52}$ detected a prevalence of $31 \%$ of ADHD in children with ASD assessed through the administration of Kiddie-SADS-PL to parents; Sikora et $\mathrm{al}^{53}$ found that $41 \%$ of children received $T$ scores $>70$ in only 1 subscale (either the Attention Problems scale or DSM-Oriented Attention Deficit Hyperactivity Problem scale) and 19\% had elevated $T$ scores in both subscales of the Child Behavior Checklist. Kaat et $\mathrm{al}^{54}$ showed that the ADHD was the most common impairing condition in children with ASD as reported by parent (67\%) and teacher (71\%) DSM-IV rating scales. The results of the current study are in line with those of previous studies. We found that $55 \%$ of ASD patients reported ADHD symptoms at CPRS-R DSM-IV total subscale, 61\% at Swanson, Nolan and Pelham Questionnaire IV Inattention and $49 \%$ at Hyperactivity/Impulsivity subscales.

Although the risk factors of autistic symptoms in children with ADHD have been investigated in some studies, ${ }^{23,41}$ studies about factors associated with ADHD symptoms in children with ASD are lacking. For this reason, in the current study, we probed the impact of coexisting somatic or neuropsychiatric problems, familiar predictors and pregnancy factors on ADHD symptoms in children with ASD. At first, we conducted our analyses distinguishing between coexisting somatic or neuropsychiatric problems, familiar predictors and pregnancy factors.

Regarding somatic or neuropsychiatric problems, we observed that motor delay, enuresis, allergies, ODD and intellectual disabilities comorbidities were associated with increased ADHD symptoms in children with ASD.

These results are in line with those of previous studies which showed that developmental delays in motor function could be related to ADHD symptoms. ${ }^{55,56}$ Other research found that the prevalence of enuresis is higher in children with ADHD than non-ADHD controls. ${ }^{57-59}$ In the same vein, previous studies have identified allergic diseases as possible factors associated with ADHD ${ }^{60-65}$ One possible explanation for the association between allergic diseases and ADHD is that some consequences of allergic pediatric diseases such as behavioral abnormalities and sleep disorders sometimes are so severe that they lead to easy fatigue daytime, sleepiness, inattention and impulsivity. Another hypothesis suggests the interaction between neurodevelopmental abnormalities and dysregulation of the immune system. In particular, proinflammatory cytokines, activated B-lymphocytes and NK cells, due to an abnormal stimulation of the immune system (as in autoimmune diseases, allergic diathesis), would lead to a neuronal glia response interfering with the development of different areas of the central nervous system including the 
prefrontal cortex ${ }^{64,65}$ In a study that assessed the relationship between allergic manifestations in early life and the occurrence of newly diagnosed ASD and ADHD throughout childhood, an increased risk of ASD and ADHD was found to be associated with atopic disorders in infancy; this finding suggests that a disordered immunologic response may exert effects on neurodevelopment and have implications for research into etiology and treatment strategies. ${ }^{66}$

In addition, some studies detected that ADHD and ASD were significantly positively associated with ODD-like problems in both genders, ${ }^{67-69}$ and other studies showed that children with intellectual disabilities are at least three times more likely to develop a mental disorder compared with typically developing children, with ADHD constituting the most frequent comorbid diagnosis. ${ }^{70-72}$

Taken together, these finding suggest that specific somatic or neuropsychiatric problems for ADHD could increase the ADHD symptoms in children with ASD. Concerning familial predictors, we identified neuropsychiatric family history of intellectual disabilities and psychosis as predictors of ADHD symptoms in children with ASD. The family history of intellectual disabilities in ADHD children has received less attention in prior research, and no study has addressed the occurrence of intellectual disabilities in relatives of ADHD probands. On the contrary, our results are in accord with previous studies that showed an increased risk of schizophrenia in relatives of ADHD probands. ${ }^{73,74}$ Studies about familial aggregation patterns indicate that these disorders share genetic factors which is consistent with prior twin study results for $\mathrm{ADHD}^{75}$ and schizophrenia, ${ }^{76}$ suggesting substantial heritability. This result is also interesting because ASD and ADHD have been reported to share familiarity with schizophrenia and bipolar disorder. ${ }^{77,78}$ One possible interpretation of the association between neuropsychiatric family history and ADHD symptoms in ASD children is that the mechanisms underlying intergenerational transmission could be complex and may involve a heritable common genetic and environmental liability.

Regarding pregnancy risk factors, a large and growing body of literature has demonstrated that pre-peri-postnatal complications (threatened miscarriage, preeclampsia, prenatal exposure to nicotine, low birth weight, low Apgar score, prematurity, postnatal exposure to lead) increase the risk of ADHD. ${ }^{79-84}$ However, we did not find a significant correlation with specific risk factors (maternal smoking, abortions, threatened miscarriage, infections, preeclampsia, medications during pregnancy, placental abruption, gestational diabetes, intrauterine growth retardation). Further research with a larger sample needs to examine more closely the links between ADHD and specific risk factors. In addition, we did not find a significant association between peri- and postnatal risk factors and ADHD as showed by previous research.

Moreover, the final model was created with the variables that showed an association with the increase of ADHD symptoms in children with ADHD. The final model including allergies and family history of psychosis explained $25 \%$ (corrected $R^{2}=0.25$ ) of the variance of the CPRS-R DSM-IV ADHD score. These shared factors could explain the high presence of ADHD symptoms in children with ASD. In addition, the co-presence of these factors may be used for future research investigating the impact of these factors combined together on the development of ADHD symptoms in children with ASD. However, certainly, there are other environmental factors (such as exposure to electromagnetic fields, chronic poisoning by heavy metals, aflatoxins, pesticides content in some food and other more) and also genetic factors that we have not assessed in our study, which might be related to ADHD symptoms in ASD. A research comparing individuals with both diagnoses to individuals with a single diagnosis suggests that co-occurring symptoms are associated with greater impairment than a single diagnosis; ${ }^{85}$ in fact, the co-occurring conditions may be less responsive to standard treatments for either disorder. Children with ASD and additional ADHD symptoms showed more strongly expressed autistic symptoms than participants with ASD and no additional ADHD symptoms. ${ }^{86,87}$ The present study highlights the importance of studying the relationship between the development of ADHD symptoms among children with ASD, particularly with regard to their development, as this knowledge may help to identify and treat children at a young age to minimize some of the longer-term deficits associated with the disorders. Further studies are needed to confirm this finding and explore the role of specific risk factors in the development of ADHD symptoms among individuals with ASD.

This study should be considered in the light of its limitations. One limitation of the study is the sample size that may limit the power to detect significant risk factors, especially when using regression analysis. Therefore, these results need to be interpreted with caution. Another source of uncertainty is that these familial factors were measured by interview of the parents and not by clinical diagnoses or withdrawal of data from registers. Additionally, major biases with retrospective survey studies can impact the recall of former exposure to risk variables. Among the biases which can negatively impact the veracity of retrospective surveys 
are selection bias and misclassification or information bias as a result of the retrospective aspect. Another limitation of the study is the inability to compare the males and females due to the heterogeneous distribution of the sample.

Despite these limitations, the findings of the current study represent a starting point for future research that needs to investigate the differences in rates of ADHD and associated factors between males and females with ASD, and the association between co-occurring ASD and subtype of ADHD. However, more research with larger samples and more accurate measurements of family factors needs to be undertaken before the association between risk factors and ADHD symptoms in ASD children is more clearly understood.

\section{Conclusion}

In our study, we identified some coexisting somatic or neuropsychiatric problems, familial predictors and pregnancy risk factors associated with the development of ADHD symptoms in ASD children. These factors included children's age, motor delay, enuresis, allergies, ODD and intellectual disabilities comorbidities, neuropsychiatric family history of intellectual disabilities and psychosis. Since factors associated with ADHD symptoms in children with ASD have not been investigated by other authors, further studies are needed about this topic.

\section{Abbreviations}

ADHD, attention deficit hyperactivity disorder; ADI-R, Autism Diagnostic Interview-Revised; ADOS-G, Autism Diagnostic Observation Schedule-Generic; ASD, autism spectrum disorders; BMI, body mass index; $\mathrm{CD}$, conduct disorder; CPRS-R, Conner's Parent Rating Scale-Revised; DSM-IV, Diagnostic and Statistical Manual of Mental Disorders, Fourth Edition; EEG, electroencephalogram; IQ, intelligent quotient; ODD, comorbid oppositional defiant disorder; SCQ, Social Communication Questionnaire.

\section{Acknowledgments}

The authors would like to thank all the study participants.

\section{Author contributions}

All authors contributed toward data analysis, drafting and critically revising the paper and agree to be accountable for all aspects of the work.

\section{Disclosure}

The authors report no conflict of interest in this work.

\section{References}

1. American Psychiatric Association. Diagnostic and Statistical Manual of Mental Disorders. 4th ed. Washington, DC: American Psychiatric Association; 2000.

2. Simonoff E, Pickles A, Charman T, Chandler S, Loucas T, Baird G. Psychiatric disorders in children with autism spectrum disorders: prevalence, comorbidity, and associated factors in a population-derived sample. J Am Acad Child Adolesc Psychiatry. 2008;47(8):921-929.

3. Goldstein S, Schwebach AJ. The comorbidity of pervasive developmental disorder and attention deficit hyperactivity disorder: results of a retrospective chart review. J Autism Dev Disord. 2004;34(3):329-339.

4. Gadow KD, DeVincent CJ, Pomeroy J. ADHD symptom subtypes in children with pervasive developmental disorder. J Autism Dev Disord. 2006;36(2):271-283.

5. Rommelse NN, Franke B, Geurts HM, Hartman CA, Buitelaar JK. Shared heritability of attention-deficit/hyperactivity disorder and autism spectrum disorder. Eur Child Adolesc Psychiatry. 2010;19(3) 281-295.

6. Clark T, Feehan C, Tinline C, Vostanis P. Autistic symptoms in children with attention deficit-hyperactivity disorder. Eur Child Adolesc Psychiatry. 1999;8(1):50-55.

7. Leyfer OT, Folstein SE, Bacalman S, et al. Comorbid psychiatric disorders in children with autism: interview development and rates of disorders. J Autism Dev Disord. 2006;36(7):849-861.

8. Matsushima N, Miyawaki D, Tsuji H, et al. Evaluation of attentiondeficit/hyperactivity disorder symptoms in male children with highfunctioning pervasive developmental disorders. Osaka City Med J. 2008;54(1):1-10.

9. Lundström S, Chang Z, Kerekes N, et al. Autistic-like traits and their association with mental health problems in two nationwide twin cohorts of children and adults. Psychol Med. 2011;41(11):2423-2433.

10. Taurines R, Schwenck C, Westerwald E, Sachse M, Siniatchkin M, Freitag C. ADHD and autism: differential diagnosis or overlapping traits? A selective review. Atten Defic Hyperact Disord. 2012;4(3): $115-139$.

11. Solanto MV, Pope-Boyd SA, Tryon WW, Stepak B. Social functioning in predominantly inattentive and combined subtypes of children with ADHD. J Atten Disord. 2009;13(1):27-35.

12. DuPaul GJ, McGoey KE, Eckert TL, VanBrakle J. Preschool children with attention-deficit/hyperactivity disorder: impairments in behavioral, social, and school functioning. J Am Acad Child Adolesc Psychiatry. 2001;40(5):508-515.

13. Nijmeijer JS, Minderaa RB, Buitelaar JK, Mulligan A, Hartman CA, Hoekstra PJ. Attention-deficit/hyperactivity disorder and social dysfunctioning. Clin Psychol Rev. 2008;28(4):692-708.

14. Kochhar P, Batty MJ, Liddle EB, et al. Autistic spectrum disorder traits in children with attention deficit hyperactivity disorder. Child Care Health Dev. 2011;37(1):103-110.

15. Da Fonseca D, Seguier V, Santos A, Poinso F, Deruelle C. Emotion understanding in children with ADHD. Child Psychiatry Hum Dev. 2009;40(1):111-121.

16. Santosh PJ, Mijovic A. Social impairment in hyperkinetic disorderrelationship to psychopathology and environmental stressors. Eur Child Adolesc Psychiatry. 2004;13(3):141-150.

17. Buitelaar JK, van der Wees M, Swaab-Barneveld H, van der Gaag RJ. Theory of mind and emotion-recognition functioning in autistic spectrum disorders and in psychiatric control and normal children. Dev Psychopathol. 1999;11(1):39-58.

18. Cooper M, Martin J, Langley K, Hamshere M, Thapar A. Autistic traits in children with ADHD index clinical and cognitive problems. Eur Child Adolesc Psychiatry. 2014;23(1):23-34.

19. Martin J, Hamshere ML, O'Donovan MC, Rutter M, Thapar A. Factor structure of autistic traits in children with ADHD. J Autism Dev Disord. 2014;44(1):204-215.

20. Kotte A, Joshi G, Fried R, et al. Autistic traits in children with and without ADHD. Pediatrics. 2013;132(3):e612-e622. 
21. Brieber S, Neufang S, Bruning N, et al. Structural brain abnormalities in adolescents with autism spectrum disorder and patients with attention deficit/hyperactivity disorder. J Child Psychol Psychiatry. 2007; 48(12):1251-1258.

22. Asherson P; the IMAGE Consortium. Attention-deficit hyperactivity disorder in the post-genomic era. Eur Child Adolesc Psychiatry. 2004; 13 Suppl 1:I50-I70.

23. Mulligan A, Anney RJ, O'Regan M, et al. Autism symptoms in attention-deficit/hyperactivity disorder: a familial trait which correlates with conduct, oppositional defiant, language and motor disorders. $J$ Autism Dev Disord. 2009;39(2):197-209.

24. Reiersen AM, Constantino JN, Volk HE, Todd RD. Autistic traits in a population-based ADHD twin sample. J Child Psychol Psychiatry. 2007;48(5):464-472.

25. Ronald A, Simonoff E, Kuntsi J, Asherson P, Plomin R. Evidence for overlapping genetic influences on autistic and ADHD behaviours in a community twin sample. J Child Psychol Psychiatry. 2008;49(5): 535-542.

26. Sinzig J, Lehmkuhl G. What do we know about the serotonergic genetic heterogeneity in attention-deficit/hyperactivity and autistic disorders? Psychopathology. 2007;40(5):329-337.

27. Farzin F, Perry H, Hessl D, et al. Autism spectrum disorders and attention-deficit/hyperactivity disorder in boys with the fragile X permutation. J Dev Behav Pediatr. 2006;27(2 Supp1):S137-S144.

28. Miller DT, Shen Y, Weiss LA, et al. Microdeletion/duplication at $15 q 13.2 q 13.3$ among individuals with features of autism and other neuropsychiatric disorders. J Med Genet. 2009;46(4):242-248.

29. Niklasson L, Rasmussen P, Oskarsdóttir S, Gillberg C. Autism, ADHD, mental retardation and behavior problems in 100 individuals with 22q11 deletion syndrome. Res Dev Disabil. 2009;30(4):763-773.

30. Tripp G, Wickens JR. Neurobiology of ADHD. Neuropharmacology. 2009;57(7-8):579-589.

31. Dawson G, Webb SJ, Wijsman E, et al. Neurocognitive and electrophysiological evidence of altered face processing in parents of children with autism: implications for a model of abnormal development of social brain circuitry in autism. Dev Psychopathol. 2005;17(3):679-697.

32. Previc FH. Prenatal influences on brain dopamine and their relevance to the rising incidence of autism. Med Hypotheses. 2007;68(1):46-60.

33. Toda Y, Mori K, Hashimoto T, et al. Administration of secretin for autism alters dopamine metabolism in the central nervous system. Brain Dev. 2006;28(2):99-103.

34. Bakker SC, van der Meulen EM, Buitelaar JK, et al. A whole-genome scan in 164 Dutch sib pairs with attention-deficit/hyperactivity disorder: suggestive evidence for linkage on chromosomes $7 \mathrm{p}$ and 15q. Am J Hum Genet. 2003;72(5):1251-1260.

35. Hebebrand J, Dempfle A, Saar K, et al. A genome-wide scan for attention-deficit/hyperactivity disorder in 155 German sib-pairs. Mol Psychiatry. 2006;11(2):196-205.

36. Smalley SL, Kustanovich V, Minassian SL, et al. Genetic linkage of attention-deficit/hyperactivity disorder on chromosome 16p13, in a region implicated in autism. Am J Hum Genet. 2002;71(4): 959-963.

37. Autism Genome Project Consortium, Szatmari P, Paterson AD, Zwaigenbaum L, et al. Mapping autism risk loci using genetic linkage and chromosomal rearrangements. Nat Genet. 2007;39(3): 319-328.

38. Franke B, Neale BM, Faraone SV. Genome-wide association studies in ADHD. Hum Genet. 2009;126(1):13-50.

39. Reiersen AM, Constantino JN, Todd RD. Co-occurrence of motor problems and autistic symptoms in attention-deficit/hyperactivity disorder. J Am Acad Child Adolesc Psychiatry. 2008;47(6):662-672.

40. Nijmeijer JS, Hoekstra PJ, Minderaa RB, et al. PDD symptoms in ADHD, an independent familial trait? J Abnorm Child Psychol. 2009; 37(3):443-453.

41. Kröger A, Hänig S, Seitz C, Palmason H, Meyer J, Freitag CM. Risk factors of autistic symptoms in children with ADHD. Eur Child Adolesc Psychiatry. 2011;20(11-12):561-570.
42. Gadow KD, DeVincent CJ, Pomeroy J, Azizian A. Psychiatric symptoms in preschool children with PDD and clinic and comparison samples. J Autism Dev Disord. 2004;34(4):379-393.

43. Lord C, Risi S, Lambrecht L, et al. The autism diagnostic observation schedule - generic: a standard measure of social and communication deficits associated with the spectrum of autism. J Autism Dev Disord. 2000;30(3):205-223.

44. Rutter M, Le Couteur A, Lord C. Autism Diagnostic Interview, Revised. Los Angeles, CA: Western Psychological Services; 2003.

45. Rutter M, Bailey A, Lord C. The Social Communication Questionnaire. Los Angeles, CA: Western Psychological Services; 2003.

46. Wechsler D. WISC-III: Wechsler Intelligence Scale for Children. New York, NY: The Psychological Corporation; 1991.

47. Wechsler D. The Wechsler Preschool and Primary Scale of Intelligence, Third Edition (WPPSI-III). San Antonio, TX: The Psychological Corporation; 2002.

48. Roid GH, Miller LJ. Leiter International Performance Scale-Revised: Examiner's Manual. Wood Dale, IL: Stoelting Co; 1997.

49. Nobile M, Alberti B, Zuddas A. Conners' Rating Scales - Revised (Adattamento italiano). Firenze: Giunti O.S.; 2007.

50. Craig F, Margari F, Legrottaglie AR, Palumbi R, de Giambattista C, Margari L. A review of executive function deficits in autism spectrum disorder and attention-deficit/hyperactivity disorder. Neuropsychiatr Dis Treat. 2016;12:1191-1202.

51. Thapar A, Cooper M. Attention deficit hyperactivity disorder. Lancet. 2016;387(10024):1240-1250.

52. Gjevik E, Eldevik S, Fjæran-Granum T, Sponheim E. Kiddie-SADS reveals high rates of DSM-IV disorders in children and adolescents with autism spectrum disorders. J Autism Dev Disord. 2011;41(6): 761-769.

53. Sikora DM, Vora P, Coury DL, Rosenberg D. Attention-deficit/ hyperactivity disorder symptoms, adaptive functioning, and quality of life in children with autism spectrum disorder. Pediatrics. 2012; 130 Suppl 2:S91-S97.

54. Kaat AJ, Gadow KD, Lecavalier L. Psychiatric symptom impairment in children with autism spectrum disorders. J Abnorm Child Psychol. 2013;41(6):959-969.

55. Perna R, Loughan A. Early developmental delays: neuropsychological sequelae and subsequent diagnoses. Appl Neuropsychol Child. 2012; 1(1):57-62.

56. Gurevitz M, Geva R, Varon M, Leitner Y. Early markers in infants and toddlers for development of ADHD. J Atten Disord. 2014;18(1): 14-22.

57. Mellon MW, Natchev BE, Katusic SK, et al. Incidence of enuresis and encopresis among children with attention-deficit/hyperactivity disorder in a population-based birth cohort. Acad Pediatr. 2013;13(4): 322-327.

58. Yang TK, Huang KH, Chen SC, Chang HC, Yang HJ, Guo YJ. Correlation between clinical manifestations of nocturnal enuresis and attentional performance in children with attention deficit hyperactivity disorder (ADHD). J Formos Med Assoc. 2013;112(1):41-47.

59. Okur M, Ruzgar H, Erbey F, Kaya A. The evaluation of children with monosymptomatic nocturnal enuresis for attention deficit and hyperactivity disorder. Int J Psychiatry Clin Pract. 2012;16(3):229-232.

60. Hak E, de Vries TW, Hoekstra PJ, Jick SS. Association of childhood attention-deficit/hyperactivity disorder with atopic diseases and skin infections? A matched case-control study using the General Practice Research Database. Ann Allergy Asthma Immunol. 2013;111(2): 102-106.e2.

61. Tsai JD, Chang SN, Mou CH, Sung FC, Lue KH. Association between atopic diseases and attention-deficit/hyperactivity disorder in childhood: a population-based case-control study. Ann Epidemiol. 2013; 23(4):185-188

62. Shyu CS, Lin HK, Lin CH, Fu LS. Prevalence of attention-deficit/ hyperactivity disorder in patients with pediatric allergic disorders: a nationwide, population-based study. J Microbiol Immunol Infect. 2012; 45(3):237-242. 
63. Chang HY, Seo JH, Kim HY, et al. Allergic diseases in preschoolers are associated with psychological and behavioural problems. Allergy Asthma Immunol Res. 2013;5(5):315-321.

64. Gupta S, Aggarwal S, Rashanravan B, Lee T. Th1- and Th2-like cytokines in CD4+ and CD8+ T cells in autism. J Neuroimmunol. 1998; 85(1):106-109.

65. Morgan JT, Chana G, Pardo CA, et al. Microglial activation and increased microglial density observed in the dorsolateral prefrontal cortex in autism. Biol Psychiatry. 2010;68(4):368-376.

66. Van Herzeele C, Dhondt K, Roels SP, et al. Neuropsychological functioning related to specific characteristics of nocturnal enuresis. J Pediatr Urol. 2015;11(4):208.e1-e6.

67. Hazell P. Review of attention-deficit/hyperactivity disorder comorbid with oppositional defiant disorder. Australas Psychiatry. 2010;18(6): $556-559$.

68. Kerekes N, Lundström S, Chang Z, et al. Oppositional defiant- and conduct disorder-like problems: neurodevelopmental predictors and genetic background in boys and girls, in a nationwide twin study. PeerJ. 2014;2:e359.

69. Harvey EA, Breaux RP, Lugo-Candelas CI. Early development of comorbidity between symptoms of attention-deficit/hyperactivity disorder (ADHD) and oppositional defiant disorder (ODD). J Abnorm Psychol. 2016;125(2):154-167.

70. Baker BL, Neece CL, Fenning RM, Crnic KA, Blacher J. Mental disorders in five-year-old children with or without developmental delay: focus on ADHD. J Clin Child Adolesc Psychol. 2010;39(4):492-505.

71. Neece CL, Baker BL, Blacher J, Crnic KA. Attention-deficit/ hyperactivity disorder among children with and without intellectual disability: an examination across time. J Intellect Disabil Res. 2011;55(7): 623-635.

72. Neece CL, Baker BL, Lee SS. ADHD among adolescents with intellectual disabilities: pre-pathway influences. Res Dev Disabil. 2013;34(7): 2268-2279.

73. Keshavan M, Montrose DM, Rajarethinam R, Diwadkar V, Prasad K, Sweeney JA. Psychopathology among offspring of parents with schizophrenia: relationship to premorbid impairments. Schizophr Res. 2008; 103(1-3):114-120.

74. de la Serna E, Baeza I, Toro J, et al. Relationship between clinical and neuropsychological characteristics in child and adolescent first degree relatives of subjects with schizophrenia. Schizophr Res. 2010;116(2-3): 159-167.
75. Faraone SV, Perlis RH, Doyle AE, et al. Molecular genetics of attention-deficit/hyperactivity disorder. Biol Psychiatry. 2005;57(11): 1313-1323.

76. Sullivan PF, Kendler KS, Neale MC. Schizophrenia as a complex trait: evidence from a meta-analysis of twin studies. Arch Gen Psychiatry. 2003;60(12):1187-1192.

77. Larsson H, Rydén E, Boman M, Långström N, Lichtenstein P, Landén M Risk of bipolar disorder and schizophrenia in relatives of people with attention-deficit hyperactivity disorder. Br J Psychiatry. 2013;203(2) 103-106.

78. Sullivan PF, Magnusson C, Reichenberg A, et al. Family history of schizophrenia and bipolar disorder as risk factors for autism. Arch Gen Psychiatry. 2012;69:1099-1103.

79. Silva D, Colvin L, Hagemann E, Bower C. Environmental risk factors by gender associated with attention-deficit/hyperactivity disorder. Pediatrics. 2014;133(1):e14-e22.

80. Thapar A, Cooper M, Eyre O, Langley K. What have we learnt about the causes of ADHD? J Child Psychol Psychiatry. 2013;54(1):3-16.

81. Sagiv SK, Epstein JN, Bellinger DC, Korrick SA. Pre- and postnatal risk factors for ADHD in a nonclinical pediatric population. J Atten Disord. 2013;17(1):47-57.

82. Halmøy A, Klungsøyr K, Skjærven R, Haavik J. Pre- and perinatal risk factors in adults with attention-deficit/hyperactivity disorder. Biol Psychiatry. 2012;71(5):474-481.

83. Ketzer CR, Gallois C, Martinez AL, Rohde LA, Schmitz M. Is there an association between perinatal complications and attention-deficit/ hyperactivity disorder-inattentive type in children and adolescents? Rev Bras Psiquiatr. 2012;34(3):321-328.

84. Galéra C, Côté SM, Bouvard MP, et al. Early risk factors for hyperactivity-impulsivity and inattention trajectories from age 17 months to 8 years. Arch Gen Psychiatry. 2011;68(12):1267-1275.

85. Leitner Y. The co-occurrence of autism and attention deficit hyperactivity disorder in children - what do we know? Front Hum Neurosci. 2014;8:268.

86. Sprenger L, Bühler E, Poustka L, et al. Impact of ADHD symptoms on autism spectrum disorder symptom severity. Res Dev Disabil. 2013; 34(10):3545-3552.

87. Craig F, Lamanna AL, Margari F, Matera E, Simone M, Margari L. Overlap Between Autism Spectrum Disorders and Attention Deficit Hyperactivity Disorder: Searching for Distinctive/Common Clinical Features. Autism Res. 2015;8:328-337.
Neuropsychiatric Disease and Treatment

\section{Publish your work in this journal}

Neuropsychiatric Disease and Treatment is an international, peerreviewed journal of clinical therapeutics and pharmacology focusing on concise rapid reporting of clinical or pre-clinical studies on a range of neuropsychiatric and neurological disorders. This journa is indexed on PubMed Central, the 'PsycINFO' database and CAS,

\section{Dovepress}

and is the official journal of The International Neuropsychiatric Association (INA). The manuscript management system is completely online and includes a very quick and fair peer-review system, which is all easy to use. Visit http://www.dovepress.com/testimonials.php to read real quotes from published authors. 